$\mathbb{T}$ periodica polytechnica

\author{
Social and Management Sciences \\ $18 / 2(2010) 79 \sqrt{89}$ \\ doi: 10.3311/pp.so.2010-2.03 \\ web: http://www.pp.bme.hu/so \\ (c) Periodica Polytechnica 2010
}

RESEARCH ARTICLE

\section{Capturing team performance differences through communication based analyses of team cognition}

\author{
Juliánna Katalin Soós / Márta Juhász
}

Received 2010-07-14

\begin{abstract}
Team cognition is shaped by team processes (such as interaction, communication) among the various multidisciplinary team members. Previous studies emphasize the importance of studying team cognition at a holistic level for tasks that require specialization of team members. In our view team cognition includes the team members' knowledge representations (individual mental and situational model) as well as those indispensable team processes that help to create and share the individual knowledge.

Our aim was to explore team performance differences by applying the holistic view of team cognition, studying team communication. After some content based static and sequential communicational analyses, we studied some specific task related communicational utterances in the case of 16 NPP operator teams in simulation environment. The results have revealed the importance of well established task relevant information collection utterances, furthermore the crucial role of coherent information flow. Results are discussed in terms of the usefulness of communication utterances in establishing, modifying accurate team knowledge, in order to describe the underlying process of team performance differences.
\end{abstract}

\section{Keywords}

team cognition - team process - communication - team performance $\cdot$ holistic view of team cognition $\cdot$ content static and sequential analyses

\section{Juliánna Katalin Soós}

Department of Ergonomics and Psychology, BME, 1117 Budapest, Magyar tudósok körútja 2. building Q., Hungary

e-mail: soosj@erg.bme.hu

\section{Márta Juhász}

Department of Ergonomics and Psychology, BME, 1117 Budapest, Magyar tudósok körútja 2. building Q., Hungary

e-mail: juhaszm@erg.bme.hu

\section{The characteristics of expert teamwork}

In the last few decades the technological development has led to the spread of complex operations in the field of work. Furthermore, the increased complexity of tasks necessitates a multioperator environment. No wonder that professional teams have started to play a crucial role in complex operations, where the team members possess roles specific knowledge, tasks. The joint work, the knowledge sharing activity of these team members enable them to accomplish tasks that are too complex for individuals.

In our work teams are distinguished from groups. A group consists of two or more individuals. A team is a special type of group, containing some members with specific and varied roles, with high degree of interdependence among members, required to perform specific task. This conceptual differentiation has been pointed out previously in the existing literature studying team work [20], [6], [2], [18].

Professional teams are highly differentiated from other teams through exclusive membership of expert specialists, where the team members represent different areas of speciality. The teams execute brief operations or missions repeatedly under technologically complex conditions, which requires extended (professional, vocational) training and preparation from the organization as well as from the individuals [9], [2].

We aim to examine professional teams working in high risk environment, such as the cockpit of an airplane, an operating room, an intensive care unit, or a nuclear power plant control room. High risk environments are environments in which there is a more than normal chance of damaging one's own life, the life of others or material property [9].

In our present study we focus on the Nuclear Power Plant (NPP) operator team's communication flow in order to identify and understand the key communicative behaviours that help to create a common professional ground, supporting the joint assessment of the current situation and developing adequate team strategies to face it. 


\section{The difficulties vs. the importance of capturing team} cognition

Recently, there seems to be an increased interest in the field of creating shared understanding, between team members' knowledge, namely team cognition. A large number of studies aimed to reveal the underlying processes, premises and consequences of this knowledge creation and distribution. Despite the numerous studies in this field there is less agreement in the definition, description, and measurement methods of team cognition.

Researchers studying team cognition are faced with the difficulty of capturing team cognition, since there is no single brain including all the team members' knowledge [17]. In the case of individuals we could be convinced by the existence of cognition, located in the brain of each individual. Measurement difficulties raise the question whether teams really have a common cognition or not. It is considerably difficult to capture team cognition, despite all the developed measurement methods, which usually involve rather than demonstrate the existence of this cognitive construct. However, it is necessary to emphasize that teams take actions as a whole unit, so they interact, communicate, distribute information, coordinate their behaviour, and take joint action. Furthermore through these processes (such as communication, coordination) teams interact, share their individual knowledge, finally establish team cognition. There is one possibility to capture team cognition at this level, through the team's observable behaviour.

The unclear, ambiguous theoretical concepts about team cognition lie behind all the measurement difficulties. Team cognition is referred to as shared knowledge [4], team knowledge [2] shared cognition [10], team cognition [17], [19], [13], common ground [21], shared mental model [23], [26], [35] team mental models [25], [34], [24].

The term team knowledge is preferred by Cooke, N. J., Salas, E., Cannon-Bowers, J. A. and Stout, R. [2]. They use the term team, instead of shared, because the concept "shared" can include apportioned knowledge, but not necessarily common knowledge. Furthermore they restrict to the term "knowledge" instead of using the expression "cognition", because they focus on a range of team knowledge: team mental model and situation model. In the present study the concept of team cognition is used with a broader view, including the mental and situation models at individual and team level, and team processes (such as communication, coordination) that help the team members to integrate their specific professional knowledge. In our present study we focus on one key team process, on communication that supports the team to integrate, update, and modify their knowledge on team level.

According to [18] team cognition is a collaborative thinking activity such as assessing the situation, resolving actual problems, designing and making decisions as an integrated unit. Cooke, N. J., Salas, E., Kiekel, P. A., \& Bell, B. [3] emphasize that team cognition emerges from the interplay of the individ- ual cognition of each team member and team process behaviour, thus team cognition is more than the sum of the individual team members' cognition.

The main question in studying teamwork in high risk environments is how the team members representing different special fields are able to operate and manage a technically complex system, in a high risk environment. According to theoretical approaches of team cognition each individual has two different models: individual mental model, which is long term knowledge (professional knowledge related to task, and team members) and individual situation model, describing a momentary, transient understanding of the current situation. In order to run a complex system it is needed to integrate the information and knowledge of the individual team members. The integration of long term knowledge, as well as the harmonisation of all the continuously changing environmental information may be attained through team process behaviour such as: communication, coordination, leadership, decision making. The interaction of team members is remarkably important, since the individual knowledge is transferred to team knowledge through these team processes. The output of this process will be two kinds of team level cognitive constructs: the team mental model, referring to the collective task and team relevant knowledge (roles and responsibilities, knowledge of teammates, skills, abilities, beliefs), and the team situation model, describing team collective understanding of the specific situation. This team situation model guides the team in assessing and interpreting cues and patterns of the current situation [2].

Analysing deeper the current literature of team cognition two different complementary views of this construct can be found. The collective view of team cognition approaches this cognitive construct as aggregated individual knowledge. Furthermore, the team knowledge may be assessed at a holistic level too, by focusing on the individuals' actions and behaviour, not only on their knowledge. Team knowledge at a holistic level is the team members' knowledge that has been processed or integrated through team behaviours such as communication, coordination or leadership [3]. On one side the collective view proved to be useful when knowledge is distributed homogenously among individuals, on the other side the holistic view is more appropriate when cognitive specialization is part of the team structure [18].

In spite of the fact that the individual knowledge may be clear and accurate, the inefficient team processes (such as communication, coordination) may impede the fusion, integration of these knowledge structures, leading to inaccurate team knowledge, inappropriate team action. This line of reasoning points out the importance of holistic approach of team cognition. Thus our view about team cognition holds this construct as the collection of individual situation and mental models, as well as those team processes that help the establishment and modification of team situation and mental models.

Team cognition guides the team in assessing the cues of situation, determining strategies, taking appropriate actions. Team 
Fig. 1. Team cognition framework (adaptation according to team knowledge framework of [3] and team situation awareness framework of 6

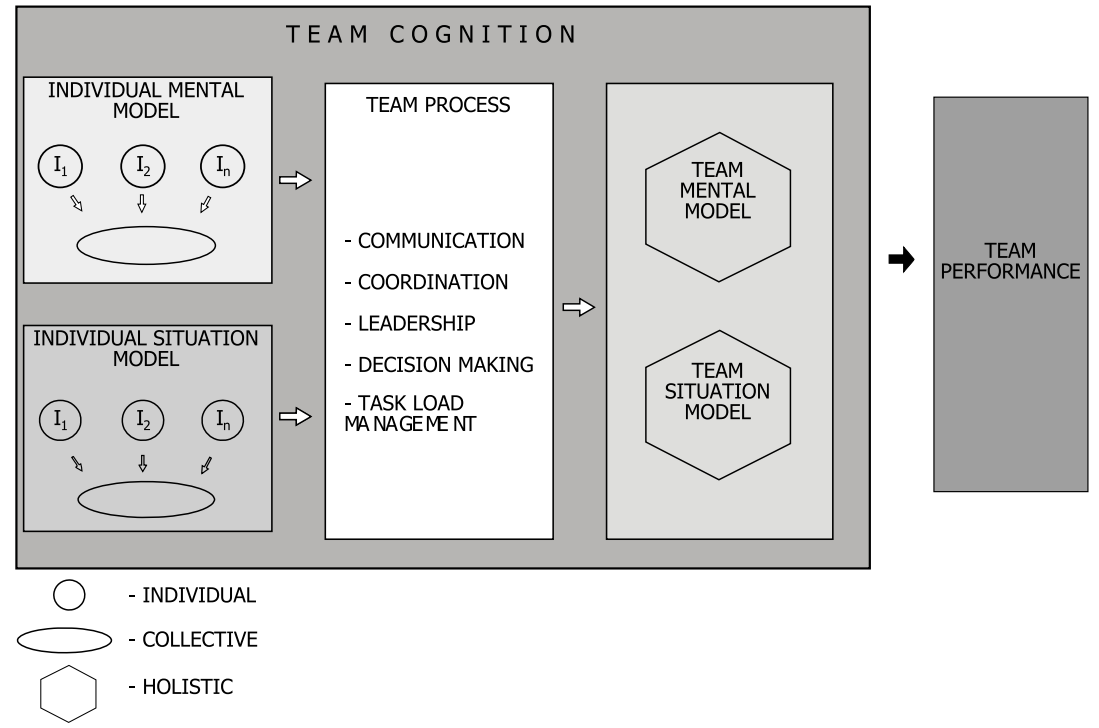

performance will be maximized to the extent that team knowledge is accurate, appropriately apportioned among members, structured in a way that supports the development of effective strategies [2]. In turn the team coordination may influence the team process. An unsuccessful performance result may urge the team to change their communication, or decisions.

\section{Team cognition and performance}

Myriads of conceptual work, as well as empirical research focus on the effects of team cognition on team performance. Klimoski and Mohammed [20] provide a literature review that attempted to establish the relationship between the shared mental model and team performance. This conceptual relationship has been studied in different fields, such as NPP [35], with league basketball teams [34], students in simulation environment [1], [23].

Another bunch of researches in this area focuses on the effect of situation awareness on the underlying factors of team performance [27], [12], [14]. The existing empirical literature concerning different aspects of team cognition and performance points out that team cognition underlies team performance. Teams whose members had similar models about contribution and importance of task showed better project results. To review the results of these studies we also need to emphasize that the sharedness of mental models between team members correlate indirectly with team performance through team processes. Moreover, not only the overlapping knowledge counts in team performance, but also the synergy of the knowledge structures (similarity between knowledge structures, the relation among the ways various team members organize their own task knowledge). Furthermore we also need to stress out the adverse effects of the excessive shared knowledge on team performance; too much shared procedural task related knowledge (e.g. procedure to complete the task) has a negative effect on team performance.

The importance of studying team cognition in order to design a successful training or selection intervention to improve team performance has been also emphasized by some conceptual studies (Smith-Jentsch K.A., Johnston J.H., Payne S.C, 2000 [31]; Cooke, N. J., Salas, E., Kiekel, P. A., \& Bell, B., 2004 [3]; Cooke, N.J. \& Gorman, J.C., 2006 [5]).

The challenge of improving team performance lies in the complex, multiple interactive processes that shape team cognition [7]. Team cognition is shaped by those team processes -such as interaction of the team members, communication - that help integrate the team members' knowledge creating and continuously sustaining team cognition. In this way one of the critical aspects of team cognition is the team process that helps team members to create and share their individual knowledge.

\section{Communication-based measures of team cognition}

In the case of expert teams, where team members represent different special fields, it is more reasonable to view, analyze and improve team cognition at a holistic level.

In the case when the team members need to interact together using verbal or textual messaging, the holistic assessment of team cognition can be accomplished through communication analyses [5], [2], [19]. The researchers elicit the team members' thoughts by asking individuals to think aloud during performing their tasks. In the case of teams where there is less need to interrupt the team dynamics by asking the team members to vocalize their thoughts, team cognition can be measured as team members share information, talk to each other during their task accomplishment [18]. In this way communication may have similar functions for teams than cognitive processes for individuals. By observing team communication, the information flow, the content of the interaction, the process as well as the products of the team mind can directly be assessed [5].

These empirical and theoretical examinations of team cognition constitute the basic motivation of our research, to use communication analyses, including team members' dialogues, characteristics of information flow between team members as a holistic window to the process how the individual knowledge will be shared, and integrated into team knowledge. In order 
to exploit the benefits of communication analyses, the measurements should best be made in the context of ongoing team dynamics, interactions.

The team members' communication can be observed and analyzed in a variety of ways. The empirical studies of communication should focus on both the quantitative and qualitative aspects of communication, not just on the content of communication, what has been said ("are they arguing?" "are they on task?") but also on how the information was distributed among the team members, who is in the centre of communication ("how long do speech turns tend to last?" "who speaks the most?") [18].

It is useful to characterize communication measurements along two dimensions:

- "physical" data vs. "content" data,

- "static" vs. "sequential" analyses.

Physical measurements are done by trained observers, or by some specific software. The analyses tend to focus on physical quantitative aspects of communication (e.g. duration of communication). They may orient toward the sequencing and timing of communicative behaviour among team members (e.g. No. of person A speaking after person B), but may also include assessment of more static quantities, such as duration of speech for different team members during one specific period of interaction (e.g. an hour, 10 minuts), or during the complete task. Content measures are based on the transcribed communication, interaction. On the bases of transcribed information flow, focusing on what is actually being said, specific coding scheme is developed, capturing the most relevant part of the information flow, such as specific keyword indexing, word counts.

Static measurements consider the team's communication only at a given point of time (every 10 seconds), or as an aggregate of the information flow over a period of time (e.g. during a complete task accomplishment). Sequential analyses take into consideration the ongoing stream of information exchange, interaction [19], [17], [5].

All these approaches provide some important views about the team process. It could be a relevant message about team interaction if the team's communication mainly consists of rejections and only little spontaneous information during the task accomplishment (static content measurement). Even though if we take into account only the raw numbers of specific communication utterances (e.g. number of spontaneous information), we may ignore other relevant features of information flow. For example analysing the conversation context of spontaneous information (sequential content) we may draw valuable conclusion that most of the spontaneous information appear after positive verbal confirmation.

Combining physical and content, static and sequential methods provides us relevant information about the team-level process, communication that underlies team cognition [5].
Our research aim was to study the content static and sequential characteristics of the team communication related to team performance.

The following section provides a summary of the existing literature concerning aspects of communication related to the holistic aspect of team cognition and also to team performance.

\section{Links between communicational indicators of team cognition and team performance}

There have been some attempts to help expert team communication to provide adequate performance under different circumstances. Waller, Gupta, Giambatista [35] aimed to identify the adaptive communicative behaviours that help the NPP control crews to adapt flexibly to a dynamic workload environment. They claim that training these adaptive behaviours such as information collection, task prioritization, task distribution is not enough, in as much that the training per se will not allow adapting, coordinating, acting promptly and accurately. Accordingly we need to help team members to create team cognition, which helps team mates to describe, explain, and make prediction, decide which action to be taken in a dynamically changing environment. It is also stated that team members collect and share information in order to identify tasks they need to perform, and receive, collect, screen information about these tasks. Appropriate information collection allows the team to better understand the situation, the system, which will help to build a shared conceptualization of the faced problems, leading to the effective establishment of team cognition [35].

All these results suggest that teams attempting to collect more information will have an opportunity to gain, analyse, understand and make use of the relevant cues from the environment, in this way they increase the teams shared cognition about the current situation (situation awareness), thus leading to better performance. While in low performing teams the members do not aim to acquire information, they reduce their ability to perceive the relevant environmental cues and act accordingly. Furthermore it has been also found that the use of long words is negatively related to performance and positively related to rates of errors [30]. Similarly, other studies claim that the use of more complex questions loaded the working memory, which in turn increased the risk of sending and receiving erroneous messages [29]. The closed, yes/no questions are verifications, they are easy and quick to answer, in contrast with open questions ("what, why, how") that are incomplete and force the addressee to use the cognitive resources, to think and reflect.

Hypothesis 1: Therefore we hypothesize that teams who engage in more closed questioning activity that aims to gather information related to the task would perform better, as the received information will not charge the cognitive resources and also help the team to create a shared understanding of the situation. Higher performing teams will use more closed information collecting question than low performing teams, where the team members will engage in more open questions. 


\begin{tabular}{lll}
\hline & STATIC (time static) & SEQUENTIAL \\
\hline CONTENT & No. of arguments & No. of arguments followed by insults \\
PHYSICAL & Total seconds spoken & No. of person A speaking after person B \\
\hline
\end{tabular}

For the efficient information flow between team members it is also important to answer the question, to provide the information in timely manner. Thus it is necessary to emphasize the importance of the information providing activity in establishing accurate and updated team cognition during task accomplishment. It has been found in the existing literature that the increases in communication volume, in particular communication about coordination (number of coordination request), were inversely correlated with team performance, [7]. However, it may be concluded that it is not just the communication quantity that affects team performance but also the characteristics of communication such as stability, focus, object of communication, and timing.

Some of the relevant studies focusing on content and physical aspect of communication demonstrate the importance of established communication procedures for team cognition and also for performance [19], [17]. The results show that the more patterns of communication (e.g. interaction patterns between team members) appeared, the less stable was the team's communication (e.g. stability of interaction patterns), and also the less stable was their team cognition and the poorer was their performance. Furthermore we tend to assume that team communication, in order to facilitate team cognition and performance, has to be focused on the task itself, trying to catch the relevant environmental cues from the present, and use this information to project future situations in accordance with the team's goals.

It has been shown that low performing flight crews were inefficient in assessing, detecting changing situation, evaluating alternative behavioural choices and setting new task priorities (failing to establish team situation awareness). The study has also indicated that high performing crews did not work harder, did not communicate more or less than low performance teams, in this way it was not the overall level of key adaptive behaviours (information collection and transfer, prioritization, task distribution) that significantly influence performance, but the timing of these behaviours [33].

This line of reasoning suggests that the information providing activity has to be focused on relevant technical aspects of the ongoing situation, as well as to project this information to the future. If the team's communication is consistently engaged in the past, they may fail to perceive and share relevant environmental cues from the present moment.

Hypothesis 2: Thus we hypothesize that the better performing team's communication is focused more on the present and future information, additionally less on the past information, in contrast with the low performing team's communication, where the team members' communication is more oriented to the past

\section{and less to the present and future information.}

In the process of the formation of common knowledge it is not sufficient to gather and to share the information, but it is also necessary to confirm the received information. It is not only the information collection behaviour that counts, but also the acknowledgement of the received information. Beside the shared knowledge, the importance of its accuracy is also emphasized, since creating a shared cognition by itself does not lead to high performance only if the shared knowledge is accurate Heffner, Salas \& Cannon Bowers, 2000 [23], [24], [1].

In real NPP operation, the tasks are allocated to several operators, and what is even more important is that each operator has a different information source. Communication is the only way by means of which they share information with each other, in this way it is crucial to clearly perceive the information in developing and creating the team shared knowledge. One of the major characteristic of effective communication is the verbal reaction, affirmation signing that the addressee perceived the information [32]. The lack of verbal feedback may suggest that the recipient overlooked the information (that may be relevant), in this way the speaker does not know whether the information has been perceived or not.

At the same time the verbal reaffirming of information may have some important side effects, the repetition of information may increase redundancy and what is more important it strains the linguistic and cognitive resources of crew members [21].

Conceivably, the individuals who expand the cognitive resources necessary to speak more elaborately, acknowledging the received information by adding some information do so at the expense of decreased situational awareness [30]. [21] advises "Make your contribution as informative as is required, BUT do not make your contribution more informative than required". The use of simple affirmation will help the team to clarify and acknowledge the received information, in this way to establish an accurate shared understanding of the situation. Conversely the affirmation with information will overload the cognitive resources of both the information provider and receiver, creating interference, impeding the team in creating a clear shared picture of the relevant aspect of situation.

Hypothesis 3: Thus we hypothesize that teams using more simple affirmations and fewer affirmations with additional information will perform better, than low performing teams, where the team members use fewer simple affirmations and more affirmations with information.

The primary task of communication is to foster the establishment, maintenance and modification of team cognition. The complete information flow between team members is partic- 
ularly important in the joint establishment and fine tuning of shared knowledge. A coherent information flow helps the team to distribute and assimilate the relevant information related to the task and the team, establishing the coherence of the joint actions.

Coherent communication can be viewed as communication that gives an answer to a previously initiated thought. The speakers, interlocutors must recognize these thoughts, react to them, and develop new thoughts related to the previous one. This goal can be achieved only if the members of the conversation are aware of each other's needs. The coherent conversation can be viewed as continuum, there is a strong semantic connection, relation between the talk, the parts of a text, such as cause, condition, affirmation, summary. In other words, the text is hierarchically structured, each part is semantically related to other parts [21]. Analyzing the coherence of operators' conversation, Grommes P. [15] stated that the coherence can be tracked to mental processes. The operating room team members share a broad common professional knowledge which constitutes the basis to be engaged in a coherent conversation. In turn the coherent flow of information facilitates the creation of shared knowledge, common ground, which is essential for efficient joint activities [15].

Hypothesis 4: Therefore we hypothesize that teams with coherent communication flow will have higher performance, than low performing teams where the information flow is more loosely connected.

Our research goal has been to capture the underlying factors of team performance differences, relative to those characteristics of communication that may be directly linked to effective establishment, maintenance and modification of team cognition.

\section{Methods}

The data collection was based on operator team interactions analysis in the Simulator Centre of a Hungarian Nuclear Power Plant. Since communication is the central factor of our research, the empirical studies of a "lively" interaction can best be carried out by analyses of carefully chosen simulator sessions. The Hungarian NPP Simulator Centre may be considered as a realistic, high-fidelity tool that is widely used in training and examinations creating the required level of face-validity to be relevant for real life situations. The Nuclear Power Plant's operator teams consist of four professional fields requiring the interaction of six members: Unit Shift Supervisor, Reactor Operator, Turbine Operator, Field Operator, Unit Electrician, and Shift Leader. Data from 16 operator teams' interaction have been collected. Each team had to follow the same scenario, however, the operator's reaction may have led to some slight differences. Choosing the simulation, we took into consideration that the scenario had to be oriented toward communication: in this way, all team members had to be involved in solving the control task. Possessing complementary knowledge they had to share information with each other to manage the problems occurring during the simu- lated malfunctions.

In order to provide a complete picture of simulation the scenario will be described briefly ("Failure of one turbine unit"): according to the annual schedule used by instructors, a live switchover test needs to be performed, while an unjustified operation of the turbine protection occurs resulting in the failure of one turbine unit. The failure of the equipment is followed by the malfunction of the primary circuit pressure control, creating a condition that also needs to be managed. The mean duration of scenario is about 35 minutes. The scenario was divided by the instructors into 4 phases having in centre the representatives of the four main fields (electrical, turbine, reactor and shift supervisor).

\subsection{Performance evaluation}

The performance scores were made by the instructors' evaluation, both at individual and collective levels. The individual performance was based on the evaluation how the role related tasks were accomplished, using the 3 -point Likert scale (1 - poor, 2 - medium, 3 - excellent). The team performance was assessed by the instructors' impression about the teams' efficiency under the different phases of the scenario using the same 3-point Likert scale. Based on the assessments of expert instructors the data can be considered reliable.

Eliciting data from performance assessments we developed four team performance categories:

1 Excellent team: the whole team performance was evaluated excellent, through all the phases of the scenario (No. $=4$ teams).

2 Medium team: the team performance is medium continuously through all the phases of the scenario (No. $=5$ teams).

3 Unbalanced team: the team performance was varying from excellent to poor through the scenario (No. $=3$ teams).

4 Poor team: the team performance was evaluated steadily as poor through the complete scenario (No. $=4$ teams).

Video records of operators' activity during the selected scenario have been also used for collecting and analyzing data. In order to keep the operators' real life behaviour the instructor informed them at the beginning of the simulator study about video recordings during the ongoing training session, but they did not know exactly which of the programmed scenarios would be videotaped. Video recordings were made with the operators' joint consent.

All the recorded conversation of the operators was transcribed in chronological order, identifying the operators' verbal utterances. Difficulties occurred in transcribing videotapes due to communication density during some period of the interaction, much simultaneous conversation flow between members, additionally we had to face with a noisy control room environment. For all these reasons we have few blind points in the tran- 
scribed videotapes, where the speaker of some utterances cannot be identified properly.

\subsection{Communication analyses:}

In our study we aimed to capture some relevant task specific content static and sequential analyses of NPP team's communication. In order to capture the most relevant content static aspect of team communication some task specific communication dimension have been developed expanding and specifying the communication dimensions used in similar environments (Conversation Analysis by Sacks, H., [28]; Speech Act Typeinventory for the Analyses of Cockpit Communication, STACK by Diegritz and Fürst, [8], Krifka, M. 2001 [21], In: Dietrich, R., Childress, T. M., [7]). The final major communication dimensions were the following groups:

- Information collecting question: The aim of the question is information acquisition, for example asking about certain indicators or resources. This can be formulated in the following two ways:

- Open Question Information: The question is addressed in order to complete the proposition with certain information, therefore it is likely to receive a long answer. It usually starts with words like what, when, who, etc.

- Closed Question Information: The aim of this question is verification, to judge the truth of a position; therefore the answer is expressed with either a single word (yes, or no) or a short phrase. For example "Can we start the program?"

- Information Providing: the team members inform each other about some relevant aspect of the mission related to human or technical indicators. This may be grouped into three categories according to the time focus:

- Information Providing Past: The speaker informs the addressee about technological information, certain indicators that happened in the past, or about the crew's past status, personnel resources in the past.

- Information Providing Present: The speaker informs the addressee about some actual, present technological information, certain indicators, or about the crew's present status, personnel resources.

- Information Providing Future: The speaker informs the addressee about some technological information that may change in the future, foretells about certain indicators, or about his intentions and future actions.

- Affirmation: It is the manifestation of two-way communications. It may be formulated in two ways:

- Simple Affirmation: Answers to yes/no question or commands. For example affirmations, acknowledgements, acceptances, answer such as 'yes', 'no', 'ok', 'good'.

- Affirmation with Information: A feedback, reinforcement on a status report or information, or command completed with additional information.
The team communication sequential analyses focused on the coherence analyses. The anchored point of the coherence analyses was the new thought (that can be a question, information, etc.) initiated by one of the team members. The main condition of the coherent conversation is the turn-taking, taking up this thought, the interlocutor develops a new question, information or command related to the previous information. Otherwise, if an initiated thought is not taken up by any of the team members, it will be considered as a thought without turn taking.

All the communication utterances may be related to the task, suggesting that the conversation is focused on the actual task. In the case the team members' attention is not focused on the task, their conversation will contain non-task related thoughts.

\section{Results}

The results shown in Fig. 2 indicate that as the team performance increases the frequency of open information collecting questions decreases $(F=4.690, p<0.05)$. However, there was no significant relationship between the use of closed information questions and team performance, the same result has been found for open questions in both individual and team level analyses. Our first hypothesis is only partially supported by this statistics. Lower performing teams were engaged in more information collection activities, used open questions more frequently.

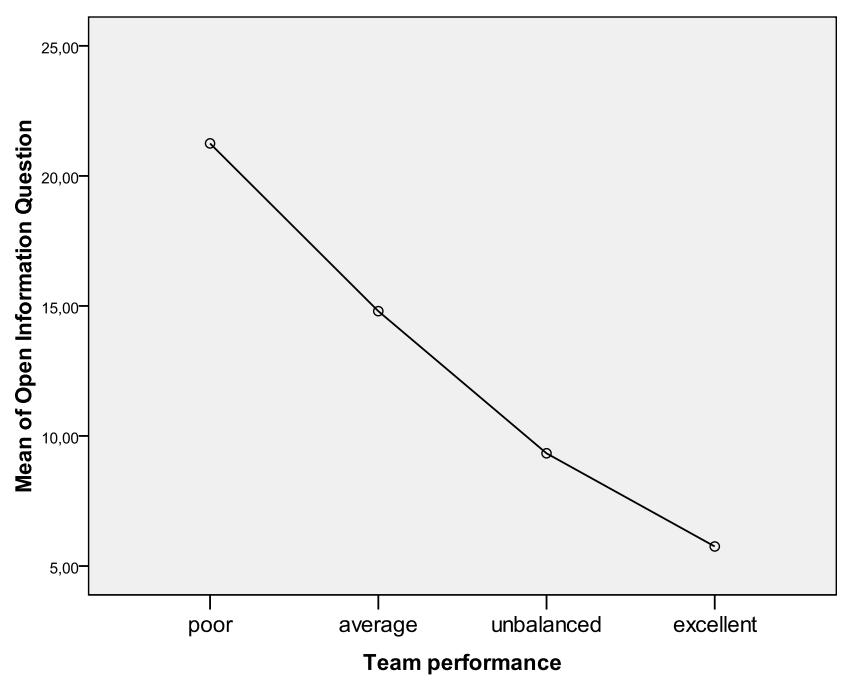

Fig. 2. The mean frequency of Open Information Question according to the team performance

The use of open questions suggests that the transmitter needs to find out more details to develop a clear picture of the situations, or about the task, team member's activity. This question makes the other person think, forcing to give a longer answer. Conceivably the good performing teams do not need to use open questions, as they hold the relevant information about the situation, task, they just need to receive an affirmation to make sure their view of the situation, to conclude the discussion before making a decision. This in turn suggests a more established 


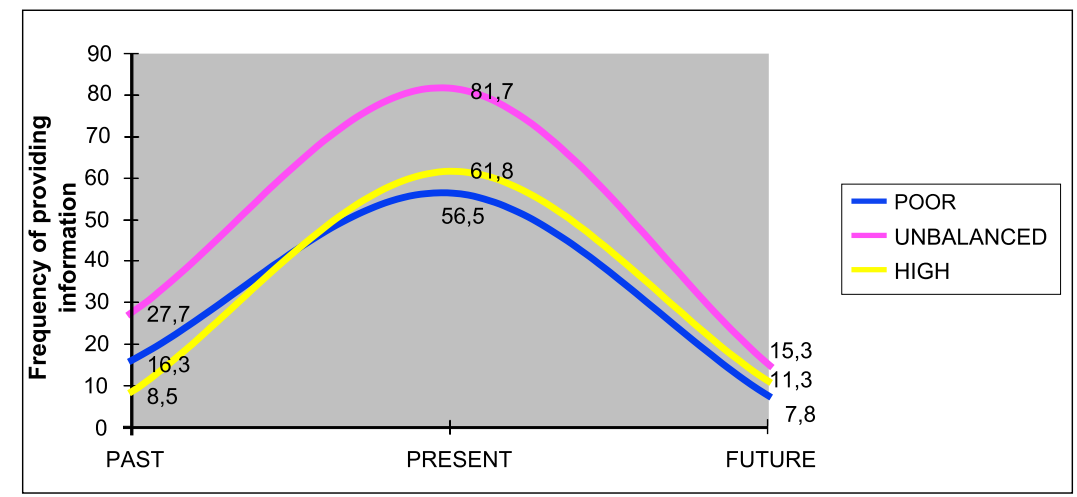

Fig. 3. The frequency of providing information about past, present, future according to team performance

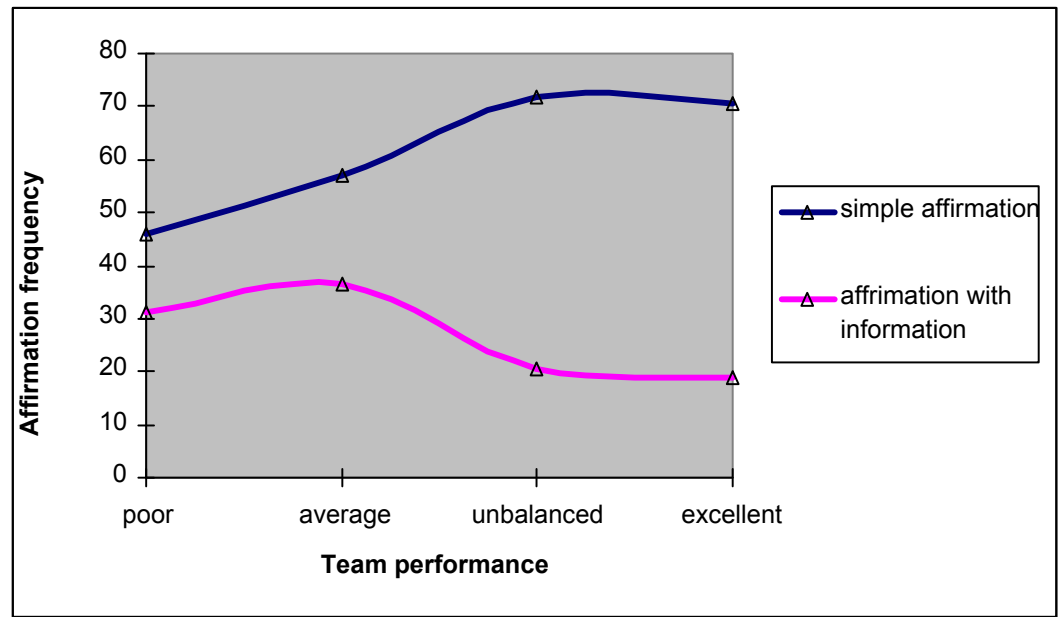

Fig. 4. The mean frequency of affirmation according to team performance

professional knowledge, possessing/holding the necessary information to resolve the acute problems.

Table 2 describes the frequency of information providing utterances focused on past, present of future according to the different level of team performance. The results indicate that excellent performing teams focus on the present during their information providing activity, also project the environmental cues to the future and orient least of all about the past. Hyphotesis 2 was partially supported, as the results show a significant relationship in the case of information providing utterances about the past $(F=4.779 p<0.05)$ and present $(F=7.109 p=0.005)$, but not in the case of information providing about the future $(F=1.337, p>0.05)$. However, the results confirm our assumption as we may observe form the Fig. 3 a tendency of poor performing teams using less, excellent teams using more future oriented information.

Focusing closely on the best, poor and unbalanced performing teams (Fig. 3) we may describe a general tendency to focus on the present, and less orientate about the past and future; at the same time there is a significant difference between the use of these communication dimension among teams with different performance. The results suggest that excellent teams succeed to perceive the environmental elements in the present, also to project the elements of the present status in the near future. Furthermore the excellent teams - compared to the other teams - focused least on the past. The unbalanced teams provide most frequently information about the past, present as well as about the future. The poor teams' information flow contains more information about past events, than excellent performing teams' communication, and less information about the presently ongoing events and about the future.

Hypothesis 3 predicts that higher performing teams would engage in more affirmation utterances, furthermore they use more simple affirmations than low performing teams, where team members engage in more affirmation with information. Fig. 4 shows that all teams use more simple affirmations, however, the excellent teams use more simple confirmations frequently and fewer affirmations with information. Although the differences are not significant, the results can be regarded as a tendency that characterizes excellent performing teams using more simple affirmations and less affirmation with information.

Finally Hypothesis 4, concerned with the relationship between coherence of information flow and team performance, was partially supported. Comparing the coherence indicators of two excellently and two poorly performing teams' dialogue, it has been explored that the poor teams' conversations include $\ll \ll \ll$.mine more thoughts without turn-taking $(t=5.506$, $p<0.05)$, and fewer thoughts with turn-taking $(t=4.069, p=$ 0.05 ) (Fig. 5). The result indicates an $======$ more thoughts without turn-taking ( $t=5.506, p<0.05)$, and fewer thoughts 
Tab. 2. The frequency of usage of providing information communication dimension about past, present, or future according to the team performance

\begin{tabular}{|c|c|c|c|c|c|}
\hline \multirow{2}{*}{ Communication dimensions } & \multicolumn{4}{|c|}{ The communication dimension frequency according to the team performance } & \multirow{2}{*}{ Significance } \\
\hline & The most frequent & Frequent & Less frequent & The most rarely & \\
\hline $\begin{array}{l}\text { Information Past } \\
F=4.779 p<0.05\end{array}$ & Unbalanced & Poor & Average & Excellent & $F=4.779 p<0.05$ \\
\hline $\begin{array}{l}\text { Information Present } \\
=======F=7.109 p= \\
0.005\end{array}$ & Unbalanced & Excellent & Poor & Average & $F=7.109 p=0.005$ \\
\hline $\begin{array}{l}\text { Information Future } \\
=======F=1.337 p> \\
0.05\end{array}$ & Unbalanced & Excellent & Poor & Average & $F=1.337 p>0.05$ \\
\hline
\end{tabular}

with turn-taking $(t=4.069, p=0.05)$ (Fig. 5). The result indicates an »»»»> .r1735 incomplete flow of information and less common ground between the poor team members. The excellent teams' dialogical conversations can be smoothly and tightly integrated, indicating coherence. In contrast, the poor performing teams' flows of conversation are loosely connected implying incoherence.

Furthermore as shown in Fig. 6, the poor performing teams use more phrases, thoughts not closely task- or problem related because of their less focus to problem, task.

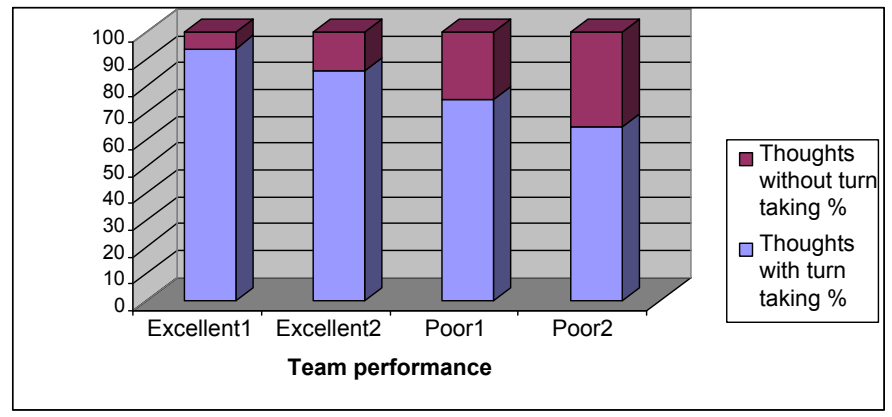

Fig. 5. The percentage of thoughts with and without turn-taking according to team performance

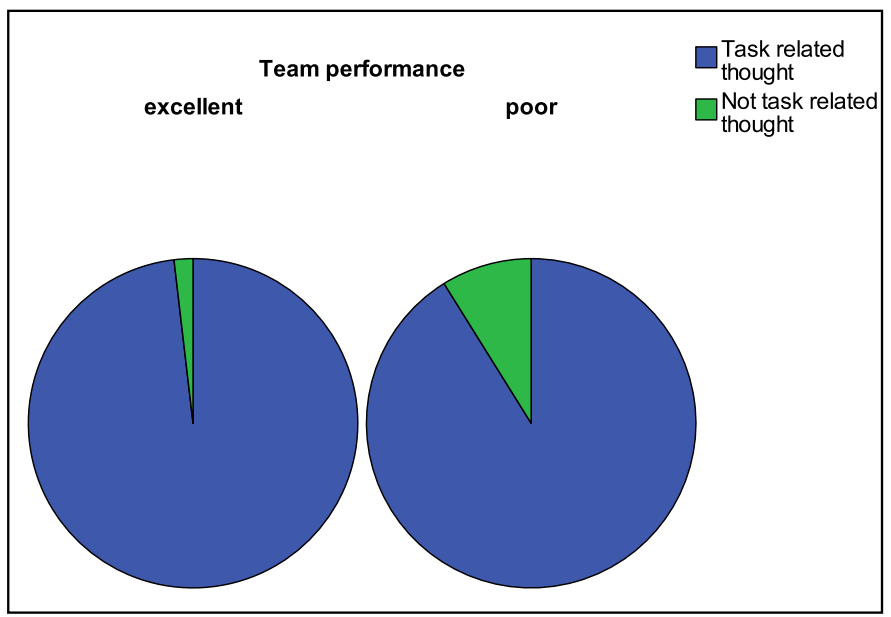

Fig. 6. The percentage of not task related and task related thoughts according to team performance

\section{Discussion}

Our research aim was to examine some characteristics of team communication related to team cognition and performance. Some specific task oriented communicative utterances proved to be crucial factors in the team processes that create and modify the common ground, namely team cognition.

In this sense, we endeavoured to capture the aspects of team processes, specifically communication that leads to the establishment of efficient team cognition underlying the productive team performance. To establish team cognition it is important how the team members collect, transfer, distribute information between each other.

The results have revealed that the excellent performing teams use fewer open information collecting questions than the low performing teams. The frequent use of open questions was associated with low performance, suggesting that when lower performing teams word their questions they have less information, knowledge about the environmental cues, so they formulate the question in a less complete form. In turn the good performing teams do not use open information questions so frequently, since they have a more stable professional knowledge about the ongoing events, being able to face the challenging of situation. However, it is necessary to emphasize the usefulness of open questions in establishing team cognition, but only during low workload, when the cognitive resources are not overloaded, so postulating an open question will not lead to any negative consequences. In this way effective communication that helps to establish team cognition, and improve performance includes the ability to apply simple and succinct vocabulary. This is also supported by the high performing teams' tendency (however not a significant result) of using more simple affirmations, and fewer affirmations with additional information, conversely with the low performing teams, where team members exchange more affirmation with information. The result indicates the need for a clear information change that helps to establish accurate team cognition, instead of creating an interference with additional, not so relevant, information.

Furthermore our analyses confirm that most of the team's communication is focused on the status, attributes, and dynamics of relevant actual elements, which could be the basis for the established awareness of their current status. Additionally for 
the efficient communication it is also important to involve in the projection of future actions, to extrapolate the ongoing information forward in time, to determine how it will affect present states of the operational environment the future. If the team fails to focus on the relevant present information, and mainly focus on the past, this could inhibit the team to capture the relevant information from the present, failing to develop a comprehensive picture of the current environment. In this way it becomes more emphasised the need to develop an established, focused communication process that supports the creation of team cognition, focusing on the relevant environmental cues from the present, and use this information to project future situations in accordance with the team's goal.

Finally, the coherent information flow between team members proved to be an efficient communication strategy to attain high performance. Coherent communication means that the team members are aware of the information distributed by others, and react to the received information (either with a simple affirmation, or with a question, or providing additional information), creating a semantic connection in the information sharing activity. In this way coherent communication is one of the key elements of the effective establishment or modification, fine tuning of accurate and complete team cognition. The conceptual chain in the conversation helps the team to focus and maintain the attention on the exchange of information, avoiding the loss of relevant information.

Our current work aims to explore and determine team performance differences based on communicational aspects of team cognition. As we emphasize the role of team processes behaviours, especially communication in establishing and modifying team cognition, a holistic view of team cognition is applied. In our view team knowledge emerges from the dynamic interaction of team members, transferring, distributing and sharing information, individual knowledge through team processes. Thus the study considers some specific content static and sequential aspects of communication that could be directly linked to establishing team knowledge, such as using open and close information questions, affirmations, information provision, and coherence of information flow.

Team members need to integrate their long term specific professional knowledge (mental model) and transient understanding of the situation (situation awareness) in order to successfully run a technologically complex system. The major indispensable criterion of efficient knowledge integration is the task oriented coherent information flow. Future research should focus on deeper sequential analyses, revealing the characteristics of coherent communication.

The results of the present study may be used as a direction for teams where the distribution, exchange of information is crucial for joint actions; even so it is difficult to generalize to all teamwork, as long as the present results are based on the analyses of teamwork in simulation environment following a particular scenario.
Our results may have some important training application in developing interventions, particularly under live circumstances such as simulation environments by focusing on, providing feedback related to some specific aspects of team communication. The use of effectively formulated information collection utterances, the development of a well established effective communication strategy that focuses on the ongoing events and projecting the environmental cues to future situations, affirming the received information could all help the team to build, modify accurate team knowledge at a holistic level and to improve team performance.

A potential problem with this approach is that it focuses on one aspect of team cognition, underlying one of the team processes: communication. Thus future work should go beyond communication, studying other team processes, such as coordination, decision making, and also capturing the professional knowledge structures, mental model, or situational awareness at both individual and team levels. Team cognition is a complex multidimensional construct, accordingly measurement and improvement endeavours should involve multiple tools.

\section{References}

1 Banks A, Millward L, Differentiating knowledge in teams: The effect of shared declarative and procedural knowledge on performance, Group Dynamics: Theory, Research \& Practice, 11, (2007.), 95-106.

2 Cooke N, Salas E, Cannon-Bowers J, Stout R, Measuring team knowledge, Human Factors, 42, (2000.), 151-173.

3 Cooke N, Salas E, Kiekel P, Bell B, Advances in measuring team cognition, Team cognition: Understanding the factors that drive process and performance (Salas E, Fiore M, eds.), American Psychological Association, Washington, DC, 2004., 83-106.

4 Cooke N, Shope S, Kiekel P, Shared-knowledge and team performance: A cognitive engineering approach to measurement, Air Force Research Laboratory. Technical report for AFOSR grant no. F49620-98-1-0287, 2001.

5 Cooke N, Gorman J, Assessment of team cognition, International encyclopedia of ergonomics and human factors - 2nd ed. (Karwowski P, ed.), Taylor \& Francis Ltd., 2006., 270-275.

6 Cooke N, Stout R, Salas E, A knowledge elicitation approach to the measurement of team situation awareness, New trends in cooperative activities: System dynamics in complex settings (McNeese M, Endsley M, eds.), Human Factors \& Ergonomics Society, Santa Monica, CA, 2001., 114-139.

7 Dietrich F, Freeman J, Entin E, MacMillan J, (In review): Modeling, measuring, and improving cognition at the team level, Proceedings of Augmented Cognition (Schmorrow D, ed.), Human Factors \& Ergonomics Society, vol. 11, Lawrence Erlbaum Associates, Las Vegas, NV, 2005., 114-139.

8 Diegritz T, Fürst C, Empirische sprechhandlungsforschung. Ansätze zur analyse und typisierung authentischer äußerungen, Erlangen: Univ. Bilbiothek, 1999., ISBN 3930357291.

9 Dietrich R, Childress T M, Group interaction in high risk environments. The GIHRE Project, Ashgate, Burlington, 2004., ISBN 9780754640110.

10 Flin R, Maran N, Identifying and training non-technical skills for teams in acute medicine, Quality \& Safety in Health Care, 13, (2004.), 180-184.

11 Fukuda R, Voggenberger T, Sträuter O, Bubb H, Analysis of communication in nuclear power plant', Annual Spring Conference of the GfA on the Occasion of the 50th Anniversary of the Foundation of the Gesellschaft für Arbeitswissenschaft e.V. (GfA) and the XVII Annual Conference of the International Society for Occupational Ergonomics \& Safety (ISOES), Quality of work and products in enterprises of the future, ISOES, 2003., 615-618. 
12 Gorman J, Cooke N, Winner J, Measuring team situation awareness in decentralized command and control environments, Ergonomics, 49(12-13), (2006.), 1312-1325.

13 Gorman J, Cooke N, Kiekel P, Dynamical perspectives on team cognition, Proceedings of the Human Factors and Ergonomics Society's Annual Meeting (Mauney S, Walker N, eds.), Vol. 48, 2004., 673-677.

14 Gorman J, Cooke N, Pederson H, Connor O, Dejoode J, Coordinated awareness of situation by teams (CAST): Measuring team situation awareness of a communication glitch, Proceedings of the Human Factors and Ergonomics Society Annual Meeting (Trafton J, Altmann M. E., Brock D, eds.), Vol. 49, 2005., 274-277.

15 Grommes P, Contributing to coherence. An empirical study of OR team communication, Proceedings of the 24th Penn Linguistics Colloquium (Minnick-Fox M, Williams A, Kaser E, eds.), Vol. 7, Univ Penn Working Papers Linguistics, 2000., 87-98.

16 Gudela G, Zala-Mező E, Group interaction in high risk environment of the Daimler-benz-Foundation. Report on the psychological part of the project, Swiss Federal Institute of Technology Zurich, 2004.

17 Kiekel P, Cooke N, Foltz P, Gorman J, Martin M, Some promising results of communication-based automatic measures of team cognition, Proceedings of the Human Factors and Ergonomics Society Annual Meeting (Sycara K, Lewis M, eds.), Vol. 46, 2002., 298-302.

18 Kiekel P, Cooke N, Human factors aspects of team cognition, The Handbook of Human Factors in Web Design (Proctor R, Vu K, eds.), Lawrence Erlbaum Associates, Mahwah, NJ, 2004., 90-103.

19 Kiekel P, Cooke N, Foltz P, Shope S, Automating measurement of team cognition through analysis of communication data, Usability evaluation and interface design (Smith M, Salvendy G, Harris D, Koubek R, eds.), Lawrence Erlbaum Associates, Mahwah, NJ, 2001., 1382-1386.

20 Klimoski R, Mohammed S, Team Mental Model: Construct or Metaphor?, Journal of Management, 20(2), (1994.), 403-437.

21 Krifka M, Structural Features of Language and Language use, Group interaction in high risk environments, The GIHRE Project (Dietrich R, Childress T, eds.), Ashgate, Burlington, 2004

22 Krifka M, Martens S, Schwarz F, Linguistic factor, Group interaction in high risk environments, The GIHRE Project (Dietrich R, Childress T, eds.), Ashgate, Burlington, 2004.

23 Mathieu J, Heffner T, Goodwin G, Salas E, Cannon-Bowers J, The influence of shared mental models on team process and performance, Journal of Applied Psychology, 85, (2000.), 273-283.

24 Mohammed S, Klimoski R, Rentsch J, The measurement of team mental models: We have no shared schema, Organizational Research Methods, 3(2), (2000.), 123-165.

25 Mohammed S, Dumville B, Team mental models in a team knowledge framework: Expanding theory and measurement across disciplinary boundaries, J. Organ. Behavior, 22, (2001.), 89-106.

26 Peterson E, Mitchell Terence R, Thompson L, Burr R, Collective Efficacy and Aspects of Shared Mental Models as Predictors of Performance Over Time in Work Groups, Group Processes Intergroup Relations, 3(3), (2000.), 296-316.

27 Roth E, Multer J, Raslear T, Shared situation awareness as a contributor to high reliability performance in railroad operations, Organization Studies, 27(7), (2006.), 967-987.

28 Sacks H, Lectures on conversation, Wiley-Blackwell, Oxford, 1992., ISBN 978-1557867056.

29 Sexton $\mathbf{J}$, The better the team, the safer the world, golden rules of group interaction in high risk environments: Evidence based suggestions for improving performance, Landenburg and Rüschlikon, 2004.

30 Sexton J, Helmreich R, Analyzing cockpit communications: The links between language, performance, error, and workload, Hum. Perfor. Extrem. Environ., 5(1), (2000.), 63-68.
31 Smith-Jentsch K, Johnston J, Payne S, Measuring team related expertise in complex environments, Making decision under stress, implications for individual and team training (Jannis A, Salas E, eds.), American Psychological Associatio, Washington DC, 2000.

32 Sträter O, Fokuda R, Communication in Nuclear Power Plants (NPP), Differentiating knowledge in teams: The effect of shared declarative and procedural knowledge on performance (Dietrich R, Childress T, Banks A, Millward L, eds.), 2004., 95-106.

33 Waller M, Giambatista R, Zellmer-Bruhn M, The effects of individual time urgency on group polychronicity, J. Managerial Psych., 14, (1999.), 244-256.

34 Webber S, Chen G, Payne S, Marsh S, Zaccaro S, Enhancing team mental model measurement with performance appraisal practices, Organizational Research Methods, 3(4), (2000.), 307-322.

35 Waller M, Gupta N, Giambatista R, Effects of Adaptive Behaviors and Shared Mental Models on Control Crew Performance, Management Science, 50(11), (2004.), 1534-1544. 